\title{
Sorption phenomena of nitroaromatic compounds in geochemical variable soils represented on the basis of column tests under in-situ conditions
}

\author{
F. Jaenig \\ Reducta Beratende Ingenieure, Dusseldorf, Germany
}

\begin{abstract}
Groundwater in the discharge area of former ammunition production facilities often reveals severe contamination by production residues and waste products. Thus, these can effect a health hazard to human beings in cases where untreated water is consumed. Based on a case study of a more than $1.5 \mathrm{~km}$ elongated contamination plume, column tests were carried out for determining the mechanisms of transportation. By using local soils taken in undisturbed cores and the contaminated local groundwater consisting of TNT, DNT, DNB, TNB, ADNT and DNN, in-situ conditions were created. Previous investigations showed that the sorption strongly correlates with the content of clay and organic matter in the soil; recent investigations additionally show the existence of complex interactions in the pristine multi-compound systems investigated. In compliance with the percentage composition of clay and organic matter, various breakthrough-curves were obtained, which imply different sorption phenomena, e.g., competitive adsorption. In particular, step-like breakthrough-curves have to be emphasised as extraordinary phenomenon.

Keywords: nitroaromatic compounds, sorption, step-like breakthrough-curves, multi-compound system.
\end{abstract}

\section{Introduction}

With the example of the WASAG explosives plant in Haltern, Germany, we have to deal with a former production area used for military production during times of war. There, from 1918 until 1922, waste waters from disintegrating 
ammunition were sunk into a deep-reaching extended aquifer of high permeability, causing a wide-spread contamination plume. The cleaning of groundwater, e.g. by pump and treat, is extremely cost-intensive because of the aquifer's high permeability. This leads us to considering natural attenuation. For this a thorough investigation of the nitroaromates' transportation mechanisms is required. Therefore, the spatial future spreading of the contamination plume must be predicted on the basis of an examination of the past spreading, which has taken place in a period of 88 years. The mass flow of the ideal tracer by way of groundwater discharge in this specific aquifer is very well known and even retardation factors $\left(R_{d}\right)$ of the nitroaromates are determined by previous investigations [1]. The $R_{d}$ of the very refined and homogeneous cretacious quartz sands of the "Halterner Sands" building up the aquifer, are dependent on smallest contents of fines and organic matter. Only small variations in these contents lead to significant variation in the retardation behaviour.

Hence, a laboratory investigation program was established by Jänig [2], in order to find out qualitatively as well as quantitatively the influence of various contents of both, fines and organic matter. This is followed by application of the results on field dimension.

\section{Laboratory investigations}

In order to receive $R_{d}$ under defined random conditions, column tests were carried out. For creating nearly pristine conditions local soils taken in undisturbed cores and the local groundwater were used. The test-fluid was gained from a well amid the contamination plume. Its chemical composition is given as follows: $25 \mu \mathrm{g} / 1 \mathrm{TNT}, 4.09 \mu \mathrm{g} / 1$ 2,3-DNT, $77.2 \mu \mathrm{g} / 1$ 2,4-DNT, $5.46 \mu \mathrm{g} / 1$ 3,4-DNT, $78.1 \mu \mathrm{g} / 1$ 1,2-DNB, $160 \mu \mathrm{g} / 1$ 1,3-DNB, $9.12 \mu \mathrm{g} / 1$ 1,4-DNB, $29.8 \mu \mathrm{g} / 1$ 2-A-4,6-DNT, $40.0 \mu \mathrm{g} / 1$ 4-A-2,6-DNT, $4.11 \mu \mathrm{g} / 1$ 1,5-DNN, $42.3 \mu \mathrm{g} / 1$ 1,8-DNN and $5.0 \mu \mathrm{g} / \mathrm{l} \mathrm{TNB}$. This is a total content of $708 \mu \mathrm{g} / \mathrm{l}$ of nitroaromatic compounds (NAC). The undisturbed core samples were available from three locations situated in the back part of the contamination plume taken from different depths of the aquifer. Hence, it was possible to choose a wide spectrum of different grain size distribution and content of organic matter of the soils. The soilmechanical and mineralogical parameters of the samples are given in table 1 .

The column tests were carried out with a hydraulic gradient of 0.669 , which is exactly 100 times the value of the natural groundwater flow in the aquifer. Breakthrough-curves (BTCs) were recorded in order to find out the timedependent behaviour of the spreading. Therefore, water samples were not only taken in a single distance from the injection level but also in 3 different levels between. For determining $\mathrm{R}_{\mathrm{d}}$ and sorption of the NACs depending on soil type and flow distance, BTCs of the almost ideal tracer $\mathrm{Cl}^{-}$were compared with the BTCs of every single analyzed NAC at every single level of a column. 
Table 1: Soil-mechanical and mineralogical parameters of the cores investigated.

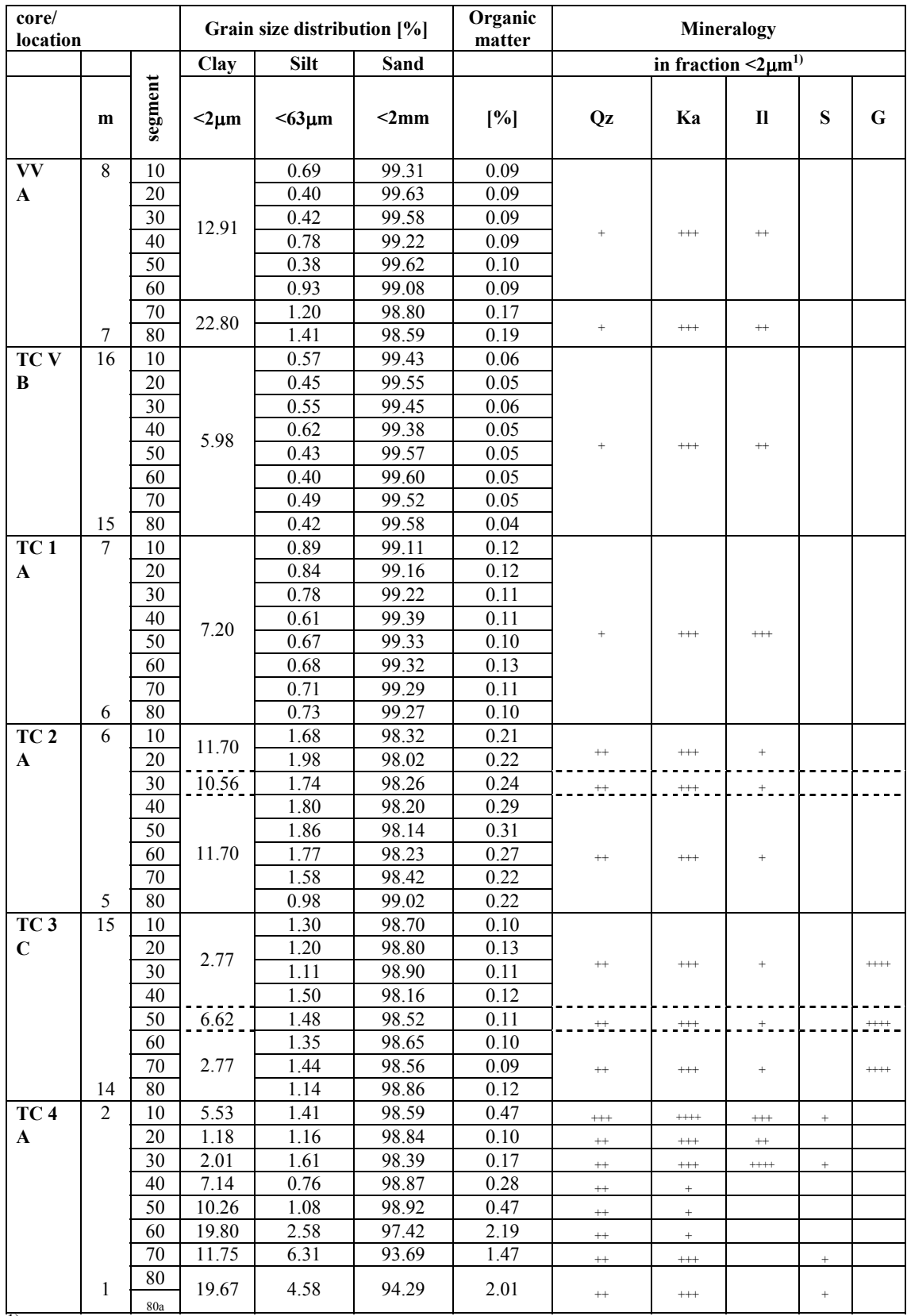

1) The procentual amounts of the fraction $<2 \mu \mathrm{m}$ are part of the fraction $<63 \mu \mathrm{m}$; because of semi-quantitative analysis by x-ray the amount of Quartz (Qz), Kaolinite (Ka), Illite (Il), Smectite (S) and Goethite (G) is only indicated by the number of + 


\subsection{Types of breakthrough-curves}

The results of the column tests indicate the existence of complex interactions in the multi-compound systems investigated: In compliance with the percentage composition of potential adsorbents in the sediment eight different main-types of BTCs were distinguished for the NACs, see figure 1. The BTCs are characterised by different sorption phenomena depending as well on the sorption on various adsorbents as on the sorbates among each other as discussed as follows:

Type 1 BTCs have a normal progression, which can show different gradient slopes, depending on the $\mathrm{R}_{\mathrm{d}}$ of the compound investigated. Because of the continuous tracer-flow a maximum concentration is received, which is equivalent to the initial concentration, respectively $\mathrm{c} / \mathrm{c}_{0}=1.0$, if standardized. These types of BTCs were mostly analyzed in the primarily ultra-pure quartzsands with few adsorbents of the columns VV and TC V and for NACs, which mainly adsorb specifically at certain adsorbents missing or are present in the soil only in very small contents.

Corresponding to an increased content of certain adsorbents specific adsorption was determined for several NACs, which result in a distinct retardation of their transportation velocity as well as in a notable deficit in their concentration in solution by adsorption. These adsorption phenomena are represented by the BTCs of type $2-4$. These BTCs were received in the adsorbent-rich soils of column TC 3 and TC 4 and in any other column for strong specifically adsorbing NACs, which quickly occupy all free places at the adsorbent and can't be displaced by any other weakly-bounding NAC.

Additionally, competitive adsorption takes place for equally-specialized NACs, resulting in a displacement of weakly-bounded NACs from the adsorbent back into solution by stronger sorbing NACs. So-caused sudden increases and decreases of the concentration in solution of 2 or even more competitive sorbates temporarily induce contrasting peaks in the BTC of the associated competitive NAC, which occasionally can exceed the concentration of the source. The described antagonistic behaviour of the sorbates is shown by the types 5 and 6 : When adsorption of one NAC starts (decreasing of type 5), desorption of another NAC takes place at the same time (increasing of type 6).

Type 7 BTCs indicate a combination of the main-types 4, 5 and 6. Therefore, they represent very strong interactions in the multi-compound system investigated. These BTCs are mainly received for strongly-bounding NACs in soils with a medium content of adsorbents.

Furthermore step-like BTCs have been detected for several NACs in the sediment of column TC 4 containing both high content of clay and organic matter. The steps are formed by multiple plateaus of nearly the same length combined with repeated increases of the gradient slope of the curve as shown with type 8 .

The types $1-7$ discussed can be found in any column and for each single NAC. Even within a single column it is possible to analyze different types of BTCs for one single NAC. On the contrary, type 8 BTCs were only detected in column TC 4 for 9 of 12 NACs. 


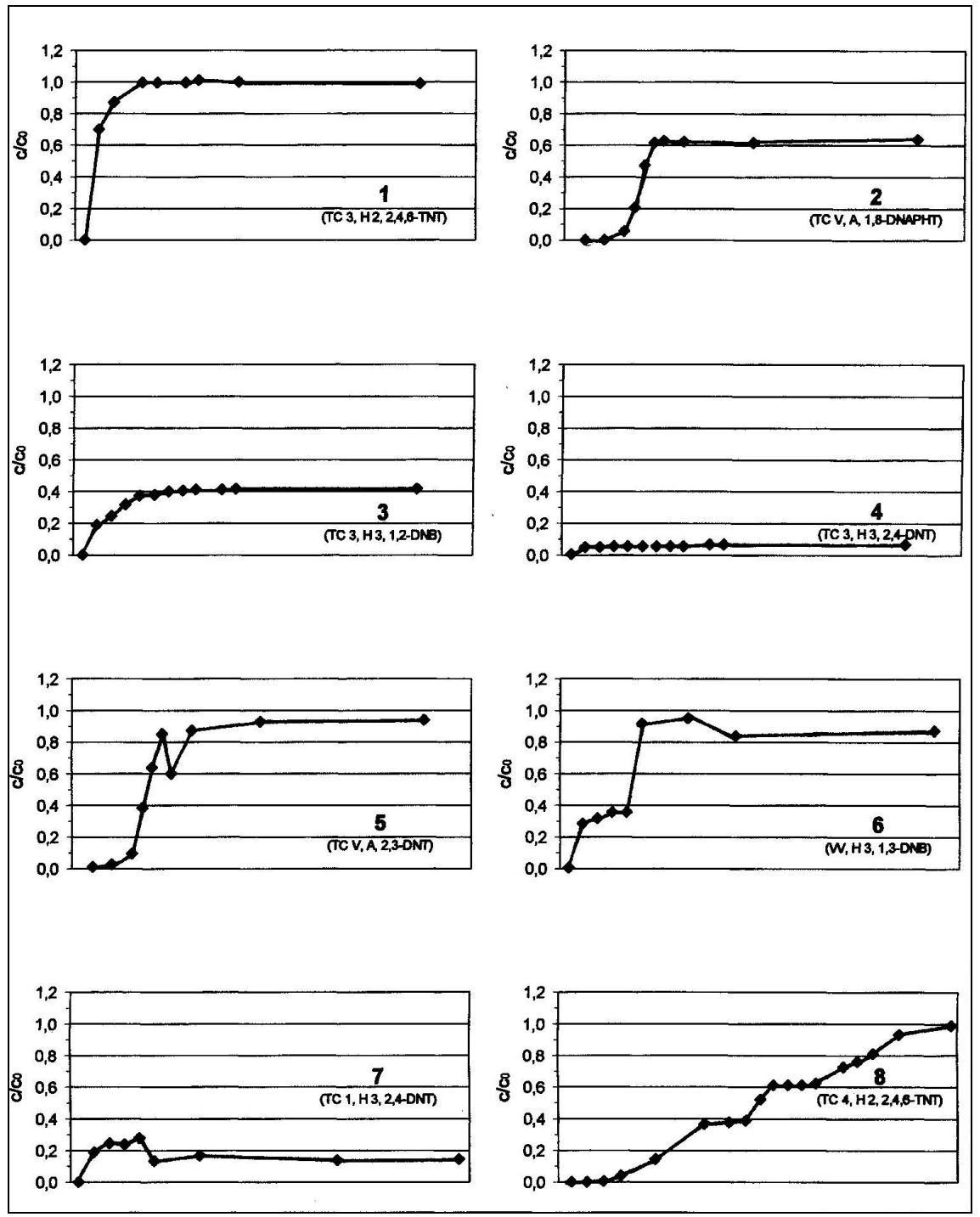

Figure 1: Main-types of breakthrough-curves.

\subsection{Step-like break-through curves (type 8)}

The step-wise breakthrough, see figure 2, which was additionally affirmed by sorption isotherms obtained from batch tests, see figure 3 , does not correspond to adsorption-models usually applied for soils. The step-wise progression is described best by step-like isotherms of type VI after Brunauer et al. [3], which have not been detected for soil-systems, yet, or by expanding the L 4respectively the S 4-type isotherms after Giles et al. [4] with at least one 
additional plateau. By assuming, that such an interpretation is valid, the type VI isotherm does correlate with a so new-defined L 5- respectively S 5-isotherm, resulting from a multi-layer-sorption.

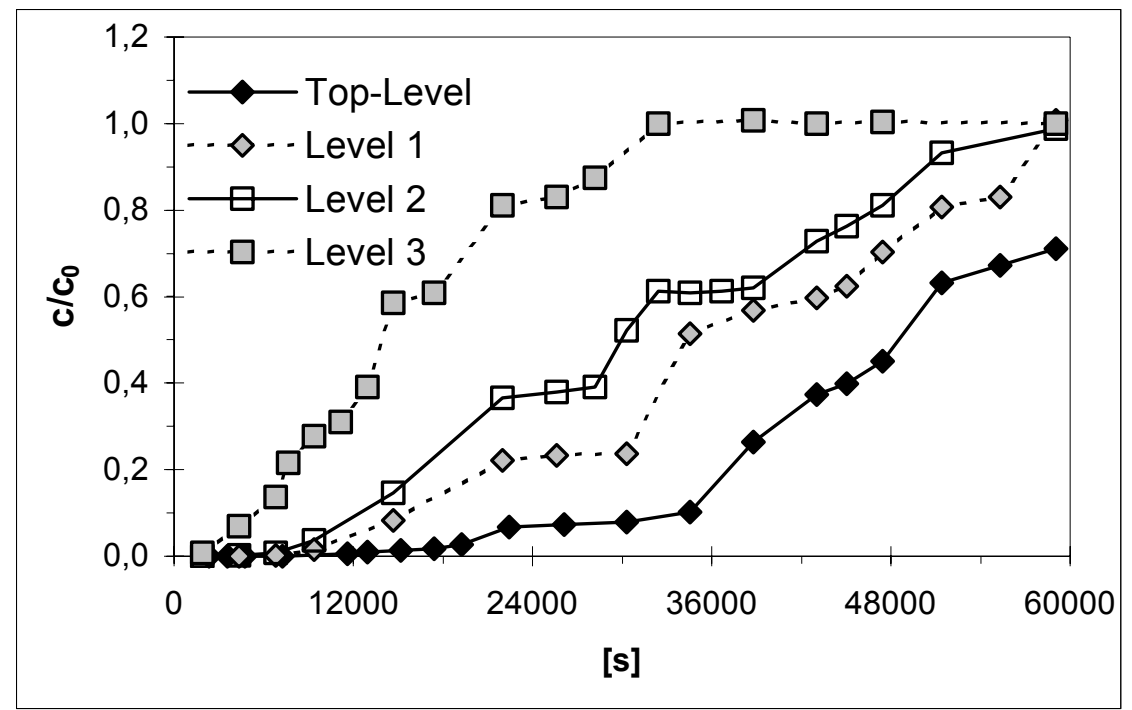

Figure 2: $\quad$ Step-like breakthrough-curves of 2,4,6-TNT; column TC 4.

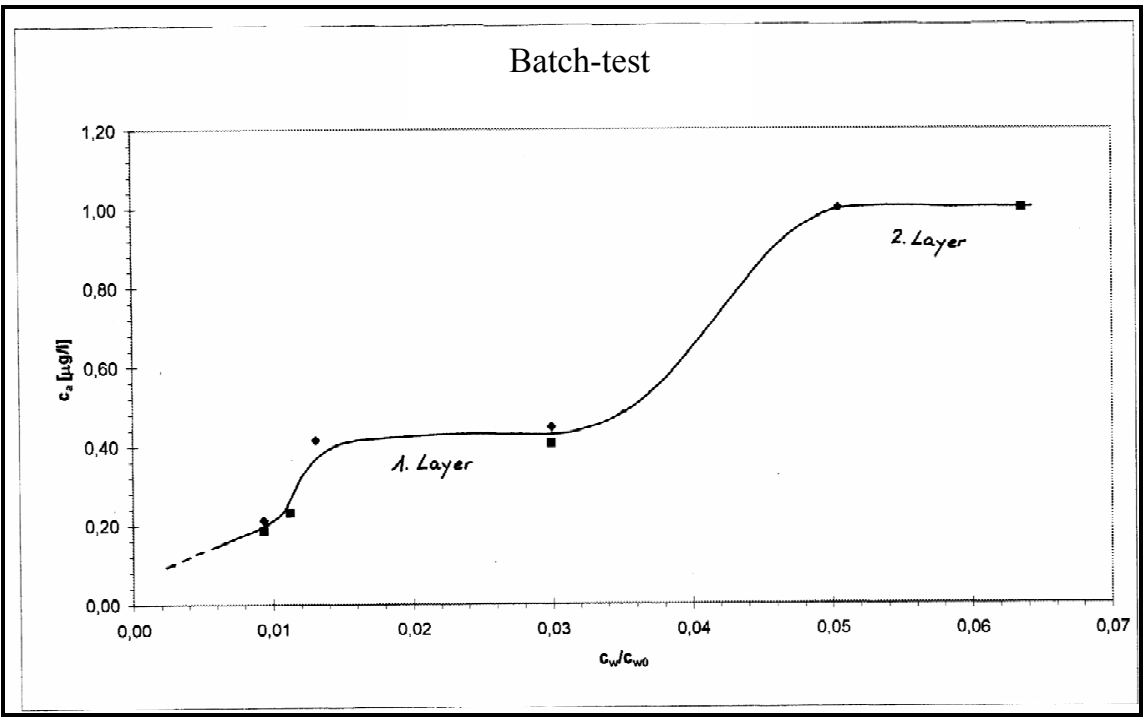

Figure 3: Isotherm for 1,5-DNN. The trend is corresponding to the $\mathrm{S} 4$ isotherm model by Giles et al. [4]. 
In a first step, multi-layer-sorption is caused by a concentration-dependent mechanical rearrangement of the sorbates at a first monolayer on the real adsorbent. In a second step, the monolayer itself can be filled with sorbates until a second layer is completed. This following occupancy is affected by a substance-dependent critical concentration of the solution. The adsorptionkinetics of the step-like BTCs imply, that multiple exceedings of the critical concentration in solution can lead to a formation of at least 3 layers. The $R_{d}$ listed in table 2 show that the physico-chemical mechanisms of the rearrangement proceed linearly: The $R_{d}$ increases corresponding to the numbers of steps respectively layers. The $R_{d}$ at level 3 show that the $R_{d}$ of any following layer $\left(R_{d L}\right)$ is in accordance with its number of order $(N)$ multiplied by the $R_{d}$ of the first step $\left(R_{d L 1}\right)$, see eqn. (1),

$$
R_{d L}=R_{d L 1} \times N
$$

Table 2: Factors of retardation for each step of the breakthrough-curves for 2,4,6-TNT; column TC 4.

\begin{tabular}{|l|c|c|c|c|}
\hline Level & $\begin{array}{c}\text { step/ } \\
\text { plateau }\end{array}$ & $\mathbf{R}_{\mathbf{d}}$ & $\begin{array}{c}\mathbf{R}_{\mathbf{d}}{ }^{*} \\
\text { (corrected } \\
\text { regarding ideal } \\
\text { tracer flow) }\end{array}$ & $\frac{t^{\prime}{ }^{\prime}{ }^{\prime}}{t^{\prime}}$ \\
\hline $\mathbf{A}$ & 1 & 6.22 & 6.50 & 1.1 \\
\hline & 2 & 11.81 & 12.15 & 1.2 \\
\hline L 1 & 3 & 15.21 & 15.61 & 1.1 \\
\hline & 1 & 7.72 & 7.87 & 1.3 \\
\hline & 2 & 15.44 & 15.21 & 1.2 \\
\hline L 2 & 3 & 22.13 & 21,76 & 1.2 \\
\hline & 1 & 11.19 & 10.28 & 1.4 \\
\hline & 2 & 20.89 & 18.47 & 1.2 \\
\hline & 3 & 29.38 & 25.56 & 1.1 \\
\hline L 3 & 4 & 35.25 & 30.53 & 1.2 \\
\hline & 1 & 8.38 & 6.60 & 1.4 \\
\hline & 2 & 16.42 & 12.05 & 1.2 \\
\hline & 3 & 24.06 & 17.07 & 1.2 \\
\hline
\end{tabular}

Step-like BTCs were obtained for TNT, 1,3-DNB and TNB at each level; for 3,4-DNT and 1,2-DNB at the higher levels; for 1,4-DNB and 4-ADNT at the lower levels and for 2-ADNT only at the lowest level of the column probably because of less running-time.

\subsection{Sorption and retardation}

Table 3 shows the differing $\mathrm{R}_{\mathrm{d}}$ for each NAC depending on the type of soil in the columns, see additionally table 1 . 
Table 3: Factors of retardation in comparison with the composition of the soils. Mean values are determined for a single column.

\begin{tabular}{|l|c|c|c|c|c|c|}
\hline $\mathbf{R}_{\mathbf{d}}$ & $\mathbf{V V}$ & TC V & TC 1 & TC 2 & TC 3 & TC 4 \\
\hline 2,4,6-TNT & 1.47 & 1.47 & 1.56 & 1.85 & 2.00 & 15.55 \\
\hline $\mathbf{2 , 3 - D N T}$ & 1.21 & 1.19 & 1.88 & 2.44 & 1.72 & 15.95 \\
\hline $\mathbf{2 , 4 - D N T}$ & 1.50 & 1.54 & 1.27 & $2.29 / 221.98$ & 1.52 & 15.29 \\
\hline 3,4-DNT & 1.25 & 1.19 & 1.59 & 2.39 & 1.85 & 20.45 \\
\hline $\mathbf{1 , 2 - D N B}$ & 1.27 & 1.21 & 7.68 & 5.24 & $2.32 / 61.91$ & 29.67 \\
\hline $\mathbf{1 , 3 - D N B}$ & 1.43 & 1.30 & 2.06 & 2.41 & 2.21 & 18.38 \\
\hline $\mathbf{1 , 4 - D N B}$ & 1.16 & 1.22 & 1.64 & 2.08 & 1.69 & 14.52 \\
\hline 2-ADNT & 1.33 & 1.15 & 1.79 & 3.44 & 1.53 & $19.79 / 39.87$ \\
\hline 4-ADNT & 1.20 & 1.15 & 1.76 & 2.67 & 1.48 & 19.61 \\
\hline 1,5-DNN & 6.78 & 1.25 & 6.53 & 32.29 & 2.05 & $12.49 / 125.06$ \\
\hline 1,8-DNN & 2.50 & 1.49 & 3.14 & 9.54 & 1.84 & $19.16 / 69,74$ \\
\hline $\mathbf{1 , 3 , 5 - T N B}$ & 1.35 & 1.50 & 1.51 & 2.02 & 1.88 & 24.29 \\
\hline
\end{tabular}

In order to find out a superior sequence of mobility, main values were determined for each NAC. Thus, the following sequence is formed (increasing $\left.\mathrm{R}_{\mathrm{d}}\right):$ 1,4-DNB $<$ 4-ADNT/TNT $<2,3-\mathrm{DNT}<3,4-\mathrm{DNT} / 1,3-\mathrm{DNB}<\mathrm{TNT} / 4-$ $\mathrm{ADNT}<2-\mathrm{ADNT} / 3,4-\mathrm{DNT}<\mathrm{TNB}<1,3-\mathrm{DNB} / 2-\mathrm{ADNT}<1,2-\mathrm{DNB} / 1,8-\mathrm{DNN}$ $<1,8-\mathrm{DNN} / 1,2-\mathrm{DNB}<1,5-\mathrm{DNN}<2,4-\mathrm{DNT}$. The sequence reveals for some NACs high and low $\mathrm{R}_{\mathrm{d}}$. This is explained by different concentrations of the sorbates in solution depending on the soil composition, at which they are preferentially adsorbed. Thus, the position partners are read as competitive partner substances. Therefore, it is evident, that competitive adsorption accelerates the field-velocity of weakly-bounded NACs.

For some NACs specific adsorption was established: 1,5-DNN and TNT adsorb on clay; 2,4-DNT, 1,2-DNB, 1,8-DNN adsorb on organic matter; 2ADNT and 4-ADNT adsorb on both, clay and organic matter; 2,4-DNT and 1,2DNB adsorb on both, organic matter and goethite. 2,3-DNT, 3,4-DNT, 1,3-DNB, 1,4-DNB and TNB do adsorb unspecifically without any preference on clay, organic matter, hydrooxides and quartz as well.

Because the part of specific sorption can't be differentiated in pristine multicompound systems, the influence on retardation of any adsorbent can't be determined quantitatively. Merely an increasing of the field-velocity is indicated, when the amount of adsorbents in the soil decreases. Therefore, in the ultra-pure quartz sands field-velocities of some ten m/a are obtained for the NACs. But in sand enriched with potential adsorbents, mobility decreases, and field-velocities of only a few $\mathrm{m} / \mathrm{a}$ can be found.

\section{Application on field dimension}

The spreading velocity of each NAC investigated was determined on the basis of the in-situ field-velocity of $v_{a}=31.5 \mathrm{~m} / \mathrm{a}$ and the calculated $\mathrm{R}_{\mathrm{d}}$, see table 5 . Because of the different $R_{d}$ the spreading varies in a wide range. This can be seen from the example given in table 6 which shows the time-dependent development of spreading along the axis of the contamination plume. 
Table 4: Spreading velocity of some of the nitroaromatic compounds investigated.

\begin{tabular}{|c|c|c|c|c|c|c|c|c|c|}
\hline \multirow{3}{*}{ NAC } & \multicolumn{3}{|c|}{$\mathbf{R}_{\mathrm{d}}$} & \multicolumn{6}{|c|}{ spreading } \\
\hline & \multirow{2}{*}{$\min ^{1}$} & \multirow{2}{*}{$\max ^{2}$} & \multirow{2}{*}{$\begin{array}{l}\text { mean } \\
\text { value }\end{array}$} & \multicolumn{2}{|c|}{$\min$} & \multicolumn{2}{|c|}{$\max$} & \multicolumn{2}{|c|}{ mean value } \\
\hline & & & & $\mathbf{m} / \mathbf{a}$ & $\mathrm{m} / \mathbf{8 8 a ^ { 3 }}$ & $\mathbf{m} / \mathbf{a}$ & $\mathrm{m} / \mathbf{8 8 a}$ & $\mathbf{m} / \mathbf{a}$ & $\mathrm{m} / \mathbf{8 8 a}$ \\
\hline $2,4,6-T N T$ & 1.47 & 15.55 & 3.98 & 21.45 & 1,888 & 2.03 & 179 & 7.92 & 697 \\
\hline 2,4-DNT & 1.50 & 221.98 & 103.76 & 21.02 & 1,850 & 0.14 & 12 & 0.30 & 26 \\
\hline 1,2-DNB & 1.21 & 61.91 & 17.83 & 26.06 & 2,293 & 1.77 & 156 & 1.77 & 156 \\
\hline 4-ADNT & 1.15 & 19.61 & 4.65 & 27.42 & 2,413 & 1.61 & 142 & 6.78 & 597 \\
\hline 1,8-DNN & 1.49 & 69.74 & 14.71 & 21.17 & 1,863 & 0.45 & 40 & 2.14 & 188 \\
\hline $1,3,5$-TNB & 1.35 & 24.29 & 5.43 & 23.36 & 2,056 & 1.30 & 114 & 5.81 & 511 \\
\hline
\end{tabular}

${ }^{1)}$ determined for the pure sands of column VV and TC V; for 1,5-DNN at column TC 3

2) determined for the enriched sands of column TC 4; for 2,4-DNT and 1,2-DNB at column TC 3

3) spreading distance after injection during 1918 and 1922

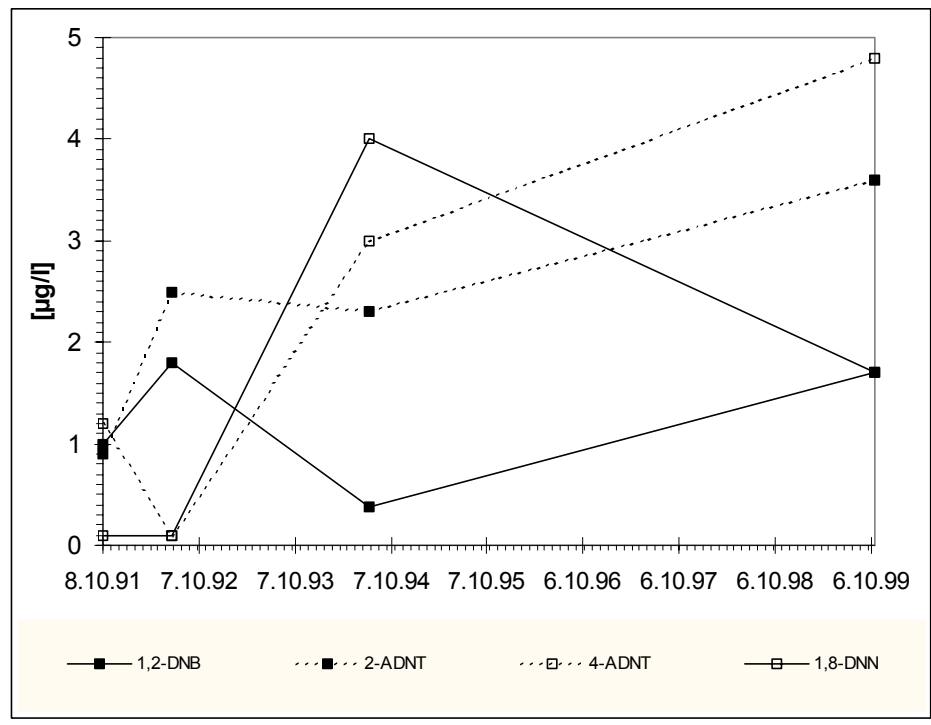

Figure 4: Competitive adsorption of some nitroaromatic compounds, observed in a well placed downstream, resulting in a timedependent variation of their distribution.

Tables 5 and 6 both show evidently the correspondence of the spreading distance calculated with the real spreading velocity in-situ. Thus, the sequence of the NACs' mobility can be transmitted on in-situ conditions as well, which is confirmed, yet, by current investigations. But the differentiation discussed is overlain by the discontinuity of the former source, the changing of sorption and release processes and competitive adsorption, see figure 4, resulting from changes in the concentration of the sorbates in solution. As a result, in every monitoring well, the distribution of contaminants varies time-dependently [2]. 
Table 5: $\quad$ Spreading of some nitroaromatic compounds in the groundwater since they have been sunk from 1918 to 1922 .

\begin{tabular}{|c|c|c|c|c|c|c|c|c|c|c|c|c|c|}
\hline NAC & 1999 & 2005 & 1999 & 2002 & 2005 & 1999 & 2004 & 1991 & 1994 & 1999 & 1991 & 1994 & 2004 \\
\hline TNT & 0.03 & bdl & 399 & 680 & 525 & 247 & 18 & 37 & 180 & 300 & 4.6 & 8.0 & 13 \\
\hline 2,4-DNT & $\mathrm{bdl}^{1)}$ & bdl & 55 & 110 & 1.2 & 5.4 & bdl & 9.5 & 12 & 9.1 & 6.6 & 21 & 345 \\
\hline 1,2-DNB & bdl & bdl & 61 & - & 61.2 & 5.8 & 57 & 1 & 0.38 & 1.7 & 79 & 150 & 827 \\
\hline 4-ADNT & 0.18 & bdl & 55 & 82 & 65.7 & 19 & 5.5 & 1.2 & 3 & 4.4 & - & 1.9 & 1.7 \\
\hline 1,8-DNN & bdll & bdl & 54 & 7.82 & 61.6 & 1.7 & 12 & - & 4 & 1.6 & - & 13 & 71 \\
\hline TNB & bdl & bdl & 1.5 & - & 7.36 & 2.5 & 1.4 & 1.5 & 120 & 48 & - & 0.28 & 1.5 \\
\hline $\mathbf{s}[\mathbf{m}]$ & \multicolumn{2}{|c|}{80} & \multicolumn{3}{|c|}{400} & \multicolumn{2}{|c|}{700} & \multicolumn{3}{|c|}{970} & \multicolumn{3}{|c|}{1,400} \\
\hline$t$ [a] & \multicolumn{2}{|c|}{2.7} & \multicolumn{3}{|c|}{13.5} & \multicolumn{2}{|c|}{23} & \multicolumn{3}{|c|}{32.3} & \multicolumn{3}{|c|}{47} \\
\hline
\end{tabular}

${ }^{1)}$ bdl.: below detection limit

\subsection{Further investigations}

The results quoted above show that the elaborate test series presented are a fundamental and indispensable basis for a prediction of the future spreadingvelocity of the plume. Therefore, they are applied on transport modelling, being carried out right now.

\section{Acknowledgement}

I thank Dr. Eulering, WASAGCHEMIE Sythen GmbH for the permission of publication.

\section{References}

[1] Jänig, F. \& Entenmann, W., Retardation of various nitroaromatic compounds in highly permeable aquifers. - Proc. of the $7^{\text {th }}$ Int. Conf. on Modelling, Measuring \& Prediction of Water Pollution, eds. C. Brebbia, D. Almorza \& D. Sales, WIT Press, Southampton, pp. 181-190, 2003.

[2] Jänig, F., Zum Transportverhalten nitroaromatischer Verbindungen in natürlichen Mehrstoff-Systemen am Beispiel eines ehemaligen Rüstungsstandortes, Diss., Math.-Naturw. Fak. Christian-Albrechts-Univ. Kiel, 2005.

[3] Brunauer, G. et al., A theory of the Van-der-Waals Adsorption of Gases. $J$. Amer. Chem. Soc., 62, pp. 1723-1732, 1940.

[4] Giles, C.H. et al., Studies in Adsorption Part XI: A System of classification of solution adsorption isotherms, and its use in diagnosis of adsorption mechanisms and in measurement of specific surface areas of solids. J. Amer. Chem. Soc., 786, pp. 3973-3993, 1960. 